\title{
The Aesthetic Unconsciousness of Flower Images in Che Yangao's Poem*
}

\author{
Guicheng Zhuang \\ Wuhan Language and Culture Research Center \\ Jianghan University \\ Wuhan, China 430056
}

\author{
Han Yan \\ Wuhan Language and Culture Research Center \\ Jianghan University \\ Wuhan, China 430056
}

\begin{abstract}
The poet Che Yangao selects and applies a large number of traditional aesthetic image, flowers in poetry creation, which can be roughly divided into two main tones and four color systems. One is a series of warm tones represented by red and yellow, and the other is a series of cool tones represented by white and purple. The images of Che Yangao's poems describe the warmth and gray of life at the same time. It shows a balance in visual effects and emotional restraint, which makes the overall poetic style show a kind of gentle warmth with cold and warm tones. The poet is drawn by an aesthetic unconsciousness in the process of creation. This unconsciousness includes both the universal spirit and historical tradition of the collective unconsciousness, as well as the individual unconsciousness influenced by the poet's life experience. Because of the influence of the collective unconsciousness, the poet will prefer the flower image in the selection of the image; because of the influence of individual unconsciousness, the poet especially favors the lotus in many flower images. The unconsciousness behind these image practice exploration and image selection has important demonstration significance for the destruction and reconstruction of the aesthetic image of contemporary poetry, showing the poet's unique aesthetic perspective and aesthetic expression.
\end{abstract}

\section{Keywords-Che Yangao; image; flower; unconsciousness}

\section{INTRODUCTION}

The development of Chinese modern poetry image has been influenced by the traditional classical poetry image and the modern Western poetic theory. It is in the process of dynamic development with the inner development rule of poetry and the pursuit of poet's own creation, namely destruction and reconstruction. This is especially true for flower image of traditional Chinese aesthetics. The modern poetry image learns from the cultural deposits of classical images, absorbs the attention of Western poetics on the ontology of poetry imagery and the liberation of poetry rhythm. Under the unique aesthetics of the poet, it gives the poetry image a new life essence and cultural connotation and shows the poet's unique poetry and thoughts, which is of great significance to the further development of modern

*This article is the result of Open Fund Project of Wuhan Language and Culture Research Center of Jianghan University - key research base of Humanities and Social Sciences in Hubei Province: "The Research on Che Yangao's Poem" poetry. The construction of flower image in poetry creation of the contemporary poet Che Yangao is the same. It can even be said to be a bold exploration and practice of modern poetry in the field of aesthetic image.

\section{THE COLORFUL FLOWER IMAGES WORLD}

"Collection of Che Yangao" (Changjiang Literature and Art Press, August 2011) is a representative works of Che Yangao's poetry, including Che Yangao's "Yearning for Warmth", "The Day is the World", "Wake the Dawn" and so on. There are a total of 413 poems. Among them, there are 104 poems about the flower image, involving up to 28 kinds of flowers, and four color systems of red, yellow, white and purple. In the poetry creation, Che Yangao selects and applies a large number of traditional aesthetic images flower. It shows the poet's love for the flower image, and makes his poetry work present a colorful and meaningful world of "flower" image.

Arnheim once said: "Color can express feelings. This is an irrefutable fact." [1] The colors close to red and yellow in hue are closer to warm tones, and the blue and white hues are closer to the cool tones. The warmth and coolness of color is judged according to the influence of color on human physiology and psychology, and the association and feelings caused by it. The tone of warmth and coolness depends mainly on the temperature of the poet's emotion. People's feelings, memories, understandings of color and their own consciousness or unconscious state are closely related to the social environment, cultural background, personal life experience, personal temperament and personality temper. The preferred color is actually a kind of psychological projection, and Che Yangao's selection of poetic image unconsciously coincides with this theory. Hegel also said: "Color reaction is a quality of all the artists. It is their unique ability to master the concept of color and tone, so it is the basic factor for the reproduction of imagination and creativity." [2] Based on the temperature of the poet's emotions, and the unique qualities of these flowers, the flower image will present the reader with different feelings. "The aroma of flowers gives people an olfactory stimulus, while the color of the flowers gives people a visual enjoyment. Here the color in nature has a certain fit and isomorphism with the cultural spirit of mankind. For example, red represents fervency and white symbolizes 
purity, etc." [3]. In general, the image of "flower" in Che Yangao's poetry can be roughly divided into two main tones: one big class is a series of warm tones represented by peach blossoms, such as "Sister, You Should Be Beautiful", "the Life is the World", "I should be drunk here", "Place where we Join Hand", etc.; another class is a series of cool tones represented by lotus flowers and snowflakes, such as "One Petal of Lotus", "Yearning for Warmth", "The Sky Can't Remember You" "Simple creates Holiness" and so on. In terms of color, the former is more intense and the latter is colder; in terms of emotion, the former is warmer and more soothing, while the latter is calmer and modest. These flower images show the field of view of the cold and warm tones, and at the same time, the flowers suggest the fate of the characters or the laws of nature, which are calm and rational in the mild.

Not only is flower image an important aesthetic element in poetry, but it forms the solidified aesthetic implication with personal temperament. The selection of the cold-tone images of snowflake and snow lotus reflects the poet's thinking about the ontology of life while the selection of warm-tone images such as peach blossom and saffron reflects the poet's pursuit of the meaning of life, which is embodied in the perfect fit of beauty of the artistic conception of oriental poetry and the beauty of western philosophy.

In the two main tones, we can observe the gradual change of color and the subtle changes in poet's emotions in the image cause the change of the tone brightness. The warm tone series can be divided into two series, red and yellow. In the red series, the images represented by peach blossoms, plum blossoms, etc., are mostly the extensions of daily life horizon based on the imagery tradition of Chinese classical poetry while the images represented by poppies and roses are the extensions of modern urban aesthetic horizon based on the influence of Western aesthetic traditions, especially the symbolic poetry tradition. In the yellow series, the image represented by rape flowers and chrysanthemum mainly comes from the nourishment of the earth's folks, which is full of the poet's deep feelings towards earth and folk. It is an extension of the folk aesthetic vision.

In the white series in the cool-tone series, the pattern of "two flowers represent respective branch" is also presented. If the images such as snow lotus and lotus represent the philosophical thinking in the realm of religious meditation and metaphysical philosophical thinking, the images represented by reed catkins and sophora flowers show the deep dive for deep thinking about life. The purple image represented by lilac and orchid contains a glimpse of the solitary gray shades far away from the dusty, which is a sudden change inward.

\section{THE BALANCE OF THE COMBINATION OF WARM AND COLD TONE IMAGE}

Under the care of aesthetic consciousness, the image combination in Zhang Yangao's poems presents a balance of beauty in visual effects and emotional restraint. At the same time, in the overall creative attitude, he writes the warmth and gray of life simultaneously, reflecting the truth of life and pointing to the warmth of life. It conforms to the main theme of the times, so that the overall poetic style presents a balanced and harmonious beauty in warm and cold tones.

In the poem "On the Ridge" depicting the scenery of the snowy terrain Tibet Plateau, "Under the white sky / black ink does not believe in the red plum blossom / in cold winter / frozen pen is still full of charm / at the highest top of the snow mountain / inspiration / extend the hand of God / to open the light of lotus for the worship", and "galsang flower opens the seductive umbrella against the blue sky", select four typical "flower" images of red plum, snow lotus, galsang flower, and snowflakes. Snow lotus and snowflake are holy, representing the world of meditation, while red plum and galsang flower are contaminated with the atmosphere of secular life. The ridge described by the poet is that of the world, away from the human world, but it is also the place where the Tibetans who have tenacious will live. They have the most devout faith in the simplest life, so that the combination of images appears a balance of beauty in contrast dimensions. At the same time, the color combination also shows a balanced aesthetic of cool and warm tones. Snow lotus and snowflake are the normal scenery of the snowy plateau. The white is pure, as if it is isolated from the earthly noisy, and does not stain a hint of smoke. The red plum that is not afraid of the cold and the brightly colored galsang flower bloom quietly in this vast and lonely land. The redness in the endless white color forms a visual abruptness, which causes a visual impact and forms a unique visual aesthetic effect and experience. It is these red spots that add the breath of warmth and human to the entire snowy plateau.

Similarly, the awareness of color balance between such image combinations is particularly prominent in The Concise Creates Holiness. "Snowing is the most ostentatious luxury in the winter / following the wind, the field is decorated into white / ... the calyx canthus, and red plum bloom in turn / golden goose yellow set off the bright red lips / it is the unique texture of the skin and blood / ... a piece of green wheat field, and the ode of earth is made." In this group of images, the white snowflakes, goose yellow plums, and red plums first show a variety of color combinations of white, red, and yellow in color combination, in which white is the main tone, red and yellow are embellishments. The vast snowy plateau under the white field of view is simple and lonely, and the appearance of red and yellow is a touch of warmth, and a rhythm of life. As the poet said, "the golden goose yellow set off the bright red lips / is the unique texture of the skin and blood." Under the balance of color, it conveys an emotional restraint. The white snow land is wide and vast, as if it is unique, with a sense of loneliness. Princess Wencheng went far away from the prosperous Datang alone and left her father and brother to marry with the emperor in Tubo. Her figure in the vast earth adds more desolation, while calyx canthus and red plum are not only the embellishment and warmth of the snowy plateau, but also the embellishment and rhythm of the pure life of the princess. The cold season gets the sense of warmth because of these creatures, so the loneliness and depression ultimately 
becomes warm. Because the image of "flower" in poetry makes the combination of images in the individual chapters show the care of balanced aesthetic consciousness in visual expression of color and the imperative intervention of the poet's subjective emotions, in addition to the beauty of balance between the image combinations presented in individual chapters, the poet's poetry style also has a balanced aesthetic sense. Behind the image world of the two main tones of warm and cold, he describes the warmth and grey of the life at the meantime. The poet said: "Poetry is another eye for me to observe society in the process of politics. With this eye, I can stay awake when I eulogizing life. My eyes won't be separated from the earth and roots, and I won't forget the other side of life, so that my writing will be closely related to the society. "[4] Some scholars once said, "In the era when confrontation no longer becomes an artistic spirit, poetry creation flows in two ways: one is the "gray" writing between "poetic" and "hostile", focusing on reality; another is yearning for warmth, looking forward to the "warmth" of opening life in daily life, and excavating the warmth of love. [5] This is a major turn in the rise of contemporary poetry after the misty poetry in the 1980 s, which is the transformation from the stream of consciousness of a few professional writers to popular stream of life. In fact, how to make the life stream creation achieve balance in its balanced aesthetics, emotional attachment and its political science is the artistic proposition that every poet may encounter as well as also a potential artistic pursuit of poet Che Yangao in poetry creation: reflecting the reality of life, but pointing and returning to the warmth of life and humanistic care. The poet said: "Excellent poets should have great wisdom, a big perspective, great compassion, and great transcendence. Their grief must be painful for society and humanity, calling for social and human awakening." [6] This balanced aesthetic is not only reflected between warm and cold tones, but also within the tone.

In the poet's works, the warm tones include "The Life is the World" full of main melody and the warmth, singing the second sister's dedication and sacrifice spirit. It is unfortunate to marry a person with a disability in the eyes of a secular person. Therefore, "big sister says that the second sister is stupid, and not worth it," but beautiful second sister not only gave up the large number of admirers and chosen the bridegroom who is a "first-class disabled soldiers and contributed one leg to the country" / but also laughed and said, "We are three-legged / with heart and heart twisting together, the life is the world". Because of this, the peach blossoms in the mountains, the peach blossoms on the faces, and the peach blossoms on the dowry are full of joy and good fortune, and full of warmth and humanity, thereby achieving a balance between artistic aesthetics and political science. There are also some gray writings that reflect and think people's living conditions in contemporary urban life, such as "lifting her leftover bottle", the dangerous atmosphere hidden behind the fiery red poppies implicates temptation in modern cities, the danger of wandering along the edge of desire, and the reality of the previous students who fell in the city of desire. However, in the poet's pen, it is not a kind of attack that exposes criticism. It is more of a kind of performance, a kind of warning, and a kind of poetic expression, so there is "I lifted up the bottle that he left / smiling, like a cleaner, pour the spoiled water / onto the enlightened head/.

In the cool tones, there is gray writing of "A Petal of Lotus" revealing of the living conditions of human beings: "The road under the foot is distinct black and white / fate is carefully walking / undulating waves are high and low / only the water droplets are simple, which proves my tininess." In real life, there are sheer cunning and falsehood and variety, and people are walking cautiously under the path of their own lives. The road under their feet is not smooth, but it is fickle and unpredictable. However, the poet did not take a hostile attitude to write life, but expressed the sentiment of life with a revelation of a lotus, thus achieving a gray writing of life. In addition, in the cool tone, there is also the warm writing that explores the beauty of the affection by opening the "warmness" in the daily life in "Longing for the Warmth". "On the summit of Mount Qomolangma / I have a piece of snowflakes borrowed from the sky/ In addition to white, there is the white snow lotus that born in the cold whether ... I am not afraid of cold, but longing for warmth.../" The white snow originally creates the lonely and deserted feeling of the mountains, but the holy snow lotus is not afraid of the cold, rooted in the mountains, sprouts, and blooms, bringing warmth to this lonely world. It is just like the arrival of Princess Wencheng that brought civilization, hope and the warmth of life to this barren land. The tenacity of natural life and the dedication of Wencheng make this unique snowcovered plateau filled with rich humanistic care and warmth.

\section{THE AESTHETIC UnCONSCIOUSNESS UNDER THE IMAGE}

Che Yangao selects and applies a large number of traditional aesthetic images - flowers in poetry creation, consciously borrows Western poetic theory when absorbing the nourishment of Chinese classical traditional aesthetics and practices the exploration of aesthetic vision of the warmtone flower image and the exploration of the aesthetic implication of the cold-tone flower image. However, now we have two questions worth considering: First, why do poets prefer flower images in many poetic images? Second, in the many flower images, why do poets especially prefer lotus?

For the first problem, the author believes that this is inseparable from the poet's aesthetic unconsciousness. Generally speaking, "color description obeys the need of spirit expression, and tends to be internalized and spiritualized from the outside to the inside, from the shallow to the deep." [7] Only when the image of poetry is given its own unique aesthetic care by the creative subject, will it give the poetry image a unique aesthetic trait, thus forming a group of poetic images with the poet's personal temperament. As a poet once said that he did not know that he wrote so many poems about the image of "flowers", which shows the infiltration and influence of the unconsciousness in the poet's creative process. The poet is drawn by an aesthetic unconsciousness in the process of creation. It can even be said that because of the influence of the collective unconscious, the poet will love the flower image in the selection of images. 
Jung revised his doctrine and proposed the concept of collective unconsciousness. He believed that unconsciousness originated from a universal spirit preserved by heredity in the history that human beings did not have written down. When reading Che Yangao's poetry, it is not difficult to find that the poet's selection and application of image is very flexible, and even a series of images appear, such as woman image, eye image, moon image, animal image, plant image, etc., but the use of flower image in plant image is particularly typical and appears in many poems. From the trace of history, aesthetics is separated from its function. Just as the aesthetics of plants began with our farming civilization, so it originally has very strong practical color. In the early days of the original Chinese classical image, the classic flower image in the poems existed in the form of figurative practical functions. Due to the low level of productivity in the primitive society, the ancestors' obedience and dependence on nature formed the life that depends on the heaven. Therefore, everything in the natural world that can serve as the source of people's food will be favored. The widely distributed flowers with numerous fruits entered the ancients' vision earlier, and the population growth in ancient times was an important support for the continuation of a race, which also derived the worship of primitive reproduction. Therefore, in the "The Book of Songs, Taoyao" article, "The peach blossoms thousands of flowers, and the color is red like fire.....The peach blossoms thousands of flowers, and peaches are big...The peach blossoms thousands of flowers, and leaves are lush..." and in "The Book of Songs, Zebo", "There are dams around the pond, with papyrus and lotus flowers in it. There is a beautiful lady over there, so I can't help loving her... There is a beautiful lady over there, whose body is slender and good... There is a beautiful lady over there, whose body is slender and graceful. , the peach and the lotus are used to compare to women based on the instinct of their species. In appearance, the beautiful and lovely peach blossom and lotus are like girls' face and its luxuriant and big fruits also contain the ancestors' expectation for more children and more blessing. Both the fruit of the peach tree and the lotus seed are the symbols of women's fecundity and the good expectation for life.

When this consciousness is rooted in the memory of the race and combined with the creation of the literati, it forms an aesthetic tradition with a unique oriental charm. The first reason why flowers become the most vivid image is that the color, aroma and posture of flowers are the most attractive, fully mobilizing the people's aesthetic feelings of vision, touch, and smell and so on, which lead people to have a rich association. The second reason is that the aesthetics behind the flower image touches the ultimate concern of human beings for life. The process of growing to falling is obvious and rapid, which easily evoke the human's feelings to life and the resonance of human beings. The blooming and falling of the flower coincide with the cultural connotation of "unity of heaven and man" in ancient China, which is the best catalyst for the literati to express feelings through things. Therefore, the flower image of has gradually developed into an important aesthetic element in the image of Chinese classical poetry. It also influenced the creation of literati in the past in the collective unconsciousness. In the literary works of future generations, the flower image also has a richer aesthetic connotation. Therefore, the poet Che Yangao loves the flower image because he is apparently influenced by the tradition of ancient Chinese poetic image, and it can be attributed to the influence of collective unconsciousness more profoundly.

Secondly, for the question why poets particularly prefer lotus image, the author believes that the poet's love for the lotus image is due to the influence of personal unconsciousness with Zen Buddhism thoughts of "flower can represent the lives in the world while the leaf can show the life of a bodhi". As the poet himself said, "99 flowers can be seen in a good poem, and 99 colors can be seen in each flower" [8]. The poet loves lotus, writes lotus, paints lotus, and understands lotus. A piece of snow, a lotus flower can represent the world, so we should take care of the true nature of life with a poetic eye, and realize the existence of life. Freud believes that the source of beauty is in the realm of unconsciousness, and the power of artistic creation also exists in the realm of unconsciousness. He emphasized that literary creation is related to the psychological phenomenon of "daydreaming" and that "the motive force of fantasy is the unfulfilled desire. Every illusion is the satisfaction of a desire, which is a correction to the unsatisfactory reality." It is not unfounded to say that using imagination and fiction to make up for the lack of reality construct the deep motive of creation. The description of the reasons for the creation of many writers in ancient and modern China and foreign countries can show that some writers' creative motives are indeed related to it. As a firm believer in the spirit of Marxism, the poet, after being deeply influenced by the Dharma thoughts, looks at the world with the animism view, and understand the true nature of life with the existence of poetry. The development of this kind of personal unconsciousness should be inseparable from the poet's life experience. The poet experienced the hardships of childhood poverty, famine, and working in the factory, and spent six years in the snowy plateau. In the harsh environment of high oxygen deficiency, facing the undulating snow mountains, people's survival is greatly tested, and people seem to be small in the world, which leads to the thinking about the ultimate concern of life. It is also this clean world that makes the person's mind be purified, which is infected with the radiance of the Dharma, away from the hustle and bustle of the world, so the original truth of life can be found, whereby the poet's literary dream takes root here.

In the poet's poems, many of them describe the QinghaiTibet Plateau, a mysterious land influenced by the deep Buddhist thoughts. Snowflakes and snow lotus are their favorite images. The snow that blooms in the sky and the snow lotus that blooms in the mountains add a holy radiance after the reincarnation of Tibetan Buddhism and the influence of concept of life and death because of its elegant and dusty style. In "There is a kind of flower here," "On the Ridge", "concision creates holiness", "Yearning for the warmth", "Holiness of the Great Wisdom", "The Power of a Grass Bud", "Worshiping the Eighteen Ice Peaks" and so on, there are descriptions of the imagery of snowflakes and snow lotus. "Zen is a simple destination, the idea is ethereal /it 
condense into a snowflake, following imagination... fall in the kingdom of crystal, a snow lotus flower / lovely snow lotus is the child of rock/ root is wisdom, which can cultivate the Buddha's lotus throne /At the time when all living creatures are delivered from torment, the sun is born in the daytime / the ice peak melts into a drop of holy water.../"Zen, holy, reincarnation, wisdom and other Buddhist-related terms become the soul of snow and snow lotus as well as the life of this land. Another world of enlightenment behind life: "The thrilling snow lotus blooming in front of on the chest / no color, is the holiness of great wisdom / is the pure white given to the world, which won't wither." Just as the poet once painted an "Ink Lotus" a five-petal red lotus with yellow stamen and the inscription is "flowers bloom together in the quiet world without wind." The flowers bloom in the five-leaf spring, and the snow filled the cold mountain with Zen thoughts. The five-petal lotus is the lotus flower that is similar to the light of Buddha. There is a saying in the Buddha words: the lotus has two colors. One color is the life, and the other is the death. The cycle of life and death is in an instant, and the flower fall to silence. The twin lotus is rare in the world, so it has more extraordinary and sacred holiness. The poet loves the image of lotus, writes lotus and understands lotus because of Buddhism thought on the holy land of the Tibetan Plateau under the influence of Chinese traditional culture, and he express it in poem under the unconscious influence.

\section{CONCLUSION}

Che Yangao's poetry draws nourishment from classical poetry in image, language and subject matter. At the same time, it can reflect a modern poet's conscious discarding of classical poetry creation. There is innovation in terms of form and content. The poet chose a lot of "flower" image, consciously absorbed the spiritual nourishment of Chinese classical poetry and learned from Western poetic theory in the practice of creation, thus realizing the exploration of aesthetic vision and aesthetic connotation of the traditional aesthetic image flower and forming a group of poetic imagery with poetry's own temperament and a colorful "flower" image world, which shows the overall poetic style with cold and warm tones coexisting that is calm and warm, and conveys the poet's unique aesthetic perspective under the influence of unconsciousness. These explorations and practices have implications for the poetry's own poetic theory and the further development of contemporary poetic imagery theory.

\section{REFERENCES}

[1] Arnheim. Art and Visual Perception [M]. Beijing: China Social Sciences Press, 1984: 460. (in Chinese)

[2] Hegel. Aesthetics: Volume 3 [M]. Beijing: The Commercial Press, 1986: 282. (in Chinese)

[3] Xin Yanjun. Research on the Image Symbol of "Flower" in Tang and Song Dynasties[J]. Suzhou University Journal of Medical Science, 2006(5): 48. (in Chinese)

[4] Feng Yun, Kang Min. The life is the world - an exclusive interview with the poet Che Yangao [J]. Poems Selection, 2008 (7): 9. (in Chinese)
[5] Deng Xin. Daily Life, Poetry Passes — On the Life Flow Tendency of Contemporary Poetry[J].Literatures, 2012(2):22. (in Chinese)

[6] Che Yangao. I write poems in Wuhan [J]. Yan'an Literature, 2009, (1): 165. (in Chinese)

[7] Wu Xiao. The Expression of Color and the Deepening of Poetic Aesthetic Consciousness[J]. Zhejiang Social Sciences, 2002(4): 172. (in Chinese)

[8] Che Yangao, Zhou Gangshan. The Contemporary Problem of Chinese Poetry Writing $[\mathrm{J}]$. World Literature Review, 2009, (1): 19. (in Chinese)

[9] Freud. Creative writers and daydreams [A]. David Lodge. Review of the 20th Century Literature: Volume [C]. Shanghai: Shanghai Translation Publishing House, 1987: 68. (in Chinese) 